\title{
TRASCENDER LA MEMORIA
}

\section{MG. HORACIO HERNÁNDEZ ANGUITA}

Universidad Católica del Maule, Chile.

hhernand@ucm.cl

DOI: http://doi.org/10.29035/ucmaule.52.95

\section{RESUMEN}

Este ensayo da cuenta de cómo San Agustín, especialmente en el libro $X$ de su obra Confesiones, no solo logra descripciones fenomenológicas magistrales acerca de la memoria humana. El santo de Hipona trasciende y va más allá, al hacer ver que la realidad del hombre está congregada en la memoria y esta es la sede de la persona. En este sentido, no es una mera facultad más. El ser mismo del hombre como creatura es memoria, con todo su dinamismo temporal. $Y$ en la hondura insondable de la memoria, se hace patente la voz de Creador, el llamado de la verdad, la fuente originaria del ser eterno. Cuestión que aporta a la reflexión que hoy se hace sobre la memoria.

\section{ABSTRACT}

This essay gives an account of how St. Augustine, especially in book $\mathrm{X}$ of his text Confessions, not only achieves magisterial phenomenological descriptions of human memory. The saint of Hipona transcends and goes beyond, to make see that the reality of man is gathered in memory and this is the seat of the person. In this sense, it is not a mere faculty anymore. The very being of man as a creature is memory, with all its temporal dynamism. And in the unfathomable depth of memory, the voice of the Creator, the call of truth, the original source of the eternal being becomes clear. Question that contributes to the reflection that today is made about memory.

Palabras clave: memoria, hombre, Key words: memory, man, creature, creatura, ser, tiempo, trascender, Dios. being, time, transcend, God. 
Existe consenso entre los especialistas y los autores diversos para valorar los análisis psicológicos de la conciencia del yo humano en Confesiones de San Agustín. También, en apreciar la maestría que posee para narrar las observaciones de los fenómenos interiores del alma humana. Con él, podemos hacer un camino de reflexión. Se nos abren horizontes y se plantean cuestiones que poseen plena actualidad.

El obispo de Hipona muestra en forma detallada las virtualidades de la memoria especialmente en el libro $\mathrm{X}$ de Confesiones, aunque también en otras obras aborda el asunto. Hace ver la capacidad de traer al presente el pasado, a través de esos misteriosos recuerdos de algún modo registrados en los "archivos" y "cavidades". Con ello, nos adentra en el interior del hombre, en lo más hondo, allí donde "habita la verdad" trascendente que buscamos y que la re-conocemos como felicidad. Esto deriva en que el yo humano descubre en sí su carácter de creatura. El horizonte de lo creado es, a su vez, trascendido, por el mismo auto reconocimiento del Creador.

Con lo señalado, se nos plantea la siguiente interrogante: ¿estamos únicamente ante geniales y asombrosas reflexiones descriptivas de la memoria humana? Es indudable, como sostiene acertadamente Laín Estralgo, que la memoria en Agustín "es testimonio psicológico de nuestra temporeidad y de nuestra totalidad" (Laín, 1954, p. 32). ¿Qué quiere decir esto? Que la memoria nos otorga la conciencia de la continuidad vital del yo. La persona del hombre, en efecto, es una totalidad dinámica que conserva y proyecta su existencia.

Pues bien, no son meras descripciones agudas sobre la memoria. Al hacerlas, el santo africano hace algo más, que el mismo autor citado deja en claro: "la psicología de Agustín -sostiene- no es sólo analítica y descriptiva; es también, y de modo primario, existencial y ontológica" (Laín, 1954, p. 33). En efecto, considero que Agustín hace un aporte sustancial al pensamiento humano. Me refiero a que nos pone ante una evidencia del ser y dinamismo del hombre, que conviene atender. Si toda la obra de las Confesiones es un ejercicio de narrar y contar de sí ante Dios y los hombres, trayendo a colación reflexiones de variado tipo, ya sean filosóficas, teológicas, místicas, pedagógicas, espirituales, autobiográficas, culturales, etc., lo que dice relación a la memoria, nos sitúa en una comprensión metafísica del hombre, en el ámbito de una analítica existencial y ontológica, para emplear la expresión de Laín Estralgo. Y esto es una novedad, porque ahonda en el ser temporal mismo del hombre y su dinamismo existencial contenido en la memoria. 
Agustín no procede desde conceptos abstractos, sino que rastrea la realidad viva de sí, en confrontación con los demás, hasta dar con unas notas estructurales de la existencia humana y sostener que la memoria es el hombre. En efecto, el hombre es constitutivamente memoria, porque en ella se anudan e integran las facultades intelectivas, volitivas y los sentimientos. Así, todas las dimensiones humanas que son en el tiempo están reunidas y congregadas por la memoria, por ello decimos: el hombre es memoria; su existir es un gradual despliegue de la misma. No hay presente del yo consciente sin la memoria. Ni hay conocimientos, ni impresiones, ni presente consciente sin la memoria. No es posible la autocomprensión actual de sí, sin memoria. Y, lo que es más, jno hay futuro imaginado ni proyecto en el hombre sin memoria! El proyecto y la expectativa surgen desde el fondo de la memoria, así como la vocación trascendente.

Ahora bien, en la experiencia de la propia temporalidad existencial, trascender la memoria permite ir hacia lo más hondo y superior del alma. El autodescubrimiento del yo lleva a Agustín en Confesiones a sostener que la memoria, sin duda, es un poder grande y por eso produce "horror", dada la multiplicidad de las dimensiones inabarcables que posee, por su profundidad infinita. Entonces, concluye: "Y esto es el alma (animus), esto soy yo" (San Agustín, 2012, p. 431). Es decir: memoria y alma humana se identifican, incluso a tal punto, que siguiendo las reflexiones agustinianas, puede afirmarse categóricamente: yo soy memoria.

Úña Juárez, gran estudioso y traductor de Agustín, en una breve nota al capítulo 17 del libro $\mathrm{X}$ de Confesiones, y a propósito de lo que venimos afirmando, dice: "No se trata de afecciones, funciones o estratos interiores, sino del ser e identidad del yo, de la realidad subjetiva como tal: '¿Cuál es mi naturaleza? ¿Qué cosa soy?, ¿qué yo?', se pregunta Agustín: 'Quid sum?'... 'Quae natura sum?' " (San Agustín, 2012, p. 432). La memoria es, pues, la sede de la vinculación interior y arraigo del hombre en todas sus dimensiones existenciales. Esto supone la comprensión humana como totalidad, es decir, su estructura unitaria ontológica abarca grados de ser, desde lo inferior a lo superior, pero es un todo íntegro.

La memoria recibe las impresiones de todas las realidades sensibles, con ello, el hombre está vinculado al horizonte del mundo físico. Es más, las impresiones son posibles, porque puede vincularse por medio de "las puertas de los sentidos" que posee, y que le permiten sentir, pero este sentir está dotado de sentido por el mismo sentido interior, que vincula las impresiones. No son meros "datos", pues hay aquí una inteligencia que percibe. Al ver la luz que cae sobre un paisaje, recibo la impresión de la misma brillantez que hace visible el panorama. El ojo que tiene 
la condición visual es la puerta de entrada a la impresión visible, con sus formas y colores, pero tal impresión, en su unidad y sentido, la guarda y rememora el sentido interior de la memoria. La memoria guarda como luz esa realidad de ser propia en virtud de la cual es posible ver el mundo visible. Ahora bien, el hombre está vinculado al mundo visible por medio de sus sentidos. Toda la sensibilidad lo hace estar. Siento que estoy aquí. Y este sentir es en este lugar y espacialidad, con los olores, la escucha, en fin, toda mi realidad sensible. Agustín, por ejemplo, situado en la iglesia de Milán, vive la conmoción interior que le producen los cánticos litúrgicos y exclama: " $\mathrm{CCuánto} \mathrm{lloré} \mathrm{con} \mathrm{tus} \mathrm{himnos} \mathrm{y} \mathrm{cánticos,} \mathrm{conmovido} \mathrm{con}$ vehemencia (acriter) por las voces de tu iglesia modulando armoniosa! Aquellas voces penetraban, sin notarlo, en mis oídos, y la verdad fluía lentamente en mi corazón y ardía (exaestuabat) con ella el afecto de la piedad y mis lágrimas corrían y me sentía bien con ellas" (San Agustín, 2012, p. 386).

Estamos aquí ante un texto que nos ilustra muy bien la vinculación de lo que se viene recalcando. Es un recuerdo que hace Agustín de las voces que penetraban en su interior "modulando armoniosa". Si observamos bien, está el sentir que tiene nuestro pensador africano y que está marcado por la escucha. Pero escuchar una armoniosa modulación de voces, sin embargo, trae consigo una experiencia más honda, que desde luego, pasa por la conmoción. ¿En qué consiste? Que mediante un sentir afectivo, la realidad superior de la verdad se hace presente. Lo visible, se vincula a una realidad invisible. ¿Estamos abiertos para contemplar lo visible en su significación trascendente? Agustín nos hace redescubrir la admiración: que las realidades sensibles poseen este poder de conmover y maravillar y que vinculan con la realidad superior. A menudo, se alude al carácter negativo de lo sensible que en Agustín habría habido por el influjo de Plotino, el que considera toda realidad física y material como "sombra y fantasma".

Fácilmente, se identifica el lenguaje agustiniano inequívocamente neoplatónico, con el pensamiento suyo. Sin embargo, nuestro autor inaugura una valoración de la realidad visible como expresión de la bondad del Creador. No se trata, por tanto, de una degradación plotiniana de ser. Es un ámbito de la creatura inferior en cuanto al grado ontológico. Toda realidad física en virtud de su existencia es buena. En efecto, todo ser -insiste Agustín-, cualquiera sea el grado en que se halle, es bueno.

Es cierto que el hombre puede desvirtuar el vínculo con lo creado y falsear el modo en cómo se relaciona con el ámbito sensible, otorgándole a este mayor entidad, quedando, por tanto, subyugado a su dominio. Pero, que las realidades 
creadas tengan esa fuerza atrayente por su entidad y belleza, es que ellas nos permiten rastrear al que "las hizo", Dios mismo. Por otra parte, no estamos en el mundo como en un escenario. El hombre es una "pequeña parte" del mundo creado, y el vínculo de su pertenencia se hace patente, porque está en condiciones de sentirlo, descubrirlo, conocerlo y llegar, mediante la propia realidad que posee, a la verdad de "lo que es". De todo ello da testimonio la memoria, por la que el arraigo a lo creado y visible es manifiesto por las imágenes que conserva y que son motivo de estímulos permanentes.

Pero sabemos que la memoria del hombre no solo conserva las impresiones sensibles del ámbito físico. También están los conocimientos. Memoria e inteligencia corresponden a una misma unidad originaria personal, como lo es respecto al querer de la voluntad. En efecto, el hombre cuando quiere recordar, recuerda, pero, lo que recuerda, es una realidad no solo retenida, sino también conocida. Conocemos nuestros recuerdos. Queremos nuestros recuerdos. En razón de ello, podemos escoger qué recuerdos hacer y relacionar los recuerdos unos con otros, o recurrir a ellos para considerar situaciones futuras que requieren tener en cuenta experiencias vividas. La totalidad personal de hombre, integra en sí mismo todas sus facultades y potencias. Y es la memoria la que permite vincular todos los ámbitos. En efecto, por su retención del tiempo en sí mismo, la memoria se extiende desde el interior hacia los ámbitos exteriores a los que está vinculada. Por eso, en su obra sobre La Trinidad, Agustín muestra cómo las facultades anímicas del hombre son el yo integral de la persona: "Y estas tres facultades -sostiene-, memoria, inteligencia y voluntad, así como no son tres vidas, sino una vida, ni tres mentes, sino una sola mente, tampoco son tres sustancias, sino una sola sustancia (una substantia) (San Agustín, 1985, p. 513). Y más adelante agrega: "Recuerdo que tengo memoria, inteligencia y voluntad; comprendo que entiendo, quiero y recuerdo; quiero querer, recordar y entender, y al mismo tiempo recuerdo toda mi memoria, inteligencia y voluntad. Lo que de mi memoria no recuerdo no está en mi memoria. Nada existe en mi memoria tan presente como la memoria. Luego en su totalidad la recuerdo" (San Agustín, 1985, $p$, 514). Con lo cual queda establecido el carácter unitario y substancial de la persona humana, su totalidad integral constituida por los grados de ser existentes del orden creado: físico, vital y del espíritu. El hombre es esa presencia que se realiza históricamente en virtud de la memoria. Es que nada existe en su memoria tan presente como la memoria misma. Memoria que no solo se concentra en la presencia de sí. La misma presencia de sí de la memoria, es búsqueda inquieta hacia el ser perdurable y eterno. 
En el autodescubrimiento del yo se reconoce una llamada de sentido inherente al ser propio que urge a respuesta. Esta llamada puede escucharse desde todo el horizonte de los seres creados. En los sucesos grandes y pequeños de la propia existencia, donde hay encuentros y desencuentros. Esa llamada resuena una y otra vez. Es la llamada a trascender la presencia de la propia memoria y reconocer de dónde procede la voz. El hombre, así, está impelido a dar respuesta a una llamada que ha de descubrir por sí mismo. Es una llamada que se hace cada vez más trasparente y lúcida, tanto más la presencia de sí de la memoria muestra los límites, el fondo inabarcable del propio ser personal. En esa realidad consciente del carácter recibido propio de la creatura, la llamada es invitación a la respuesta libre, única e irrepetible, que implica decidir y entregarse a Aquél que llama y de quien procede la existencia.

El hombre es, pues, memoria finita que trasciende más allá del tiempo, hasta la eternidad. Lo que en palabras de Julián Marías, se resume así: "El carácter finito, limitado, insatisfactorio del hombre podría expresarse en seis palabras: ser persona es poder ser más" (Marías, 2005, p. 204). Y lo que acontece en Agustín es justamente eso: poder ser más es la capacidad propia del hombre que tiene para forjarse a sí mismo. Dotado de cierta estructura física, biológica, psicológica y espiritual, en el centro de la persona está la memoria, presencia de sí mismo, desde la cual las posibilidades de realización están dadas por la abertura de su espíritu encarnado. El hombre vinculado a los estratos físicos, biológicos, psicológicos y del espíritu -reunidos en la memoria-, es presencia en y con otras presencias, con las que construye día a día la existencia terrena.

Con todo, Agustín nos recuerda la antigua máxima "conócete a ti mismo", inscrita en el santuario de Delfos y que Sócrates hizo suya en sus enseñanzas. Sobre ello, a propósito de Agustín, dice Gilson: "Conocerse a símismo es conocerse como imagen de Dios, es conocer a Dios. En tal sentido, nuestro pensamiento es memoria de Dios, el conocimiento que en él se encuentra es inteligencia de Dios, y el amor que procede de uno y otro es amor de Dios. Hay pues en el hombre algo más profundo que el hombre. Lo más íntimo de su pensamiento (abditum mentis) no es sino el secreto inagotable de Dios mismo; como la suya, nuestra más profunda vida interior no es otra cosa que el despliegue, dentro de sí mismo, del conocimiento que un pensamiento divino tiene de sí propio y del amor con que se ama" (Gilson, 1958, p. 164). 
Un eco de este autodescubrimiento del yo, lo constituyen reflexiones contemporáneas. Una de ellas, podemos recogerla de Edith Stein en su obra Ser finito y ser eterno. Nos importan sus reflexiones, porque aquí podemos recoger resonancias del autodescubrimiento del yo agustiniano, donde la discípula de Husserl realiza un análisis fenomenológico, en confrontación con Heidegger. Por la convergencia de lo que aquí se trata, no resisto tomar las siguientes expresiones de la filósofa judía y conversa al cristianismo. Al hablar sobre el ser del yo y el ser eterno, consigna lo siguiente: "Mi ser tal como yo lo encuentro y tal como yo me encuentro en él, es un ser vano; yo no existo por mí mismo y por mí mismo nada soy; me encuentro a cada instante ante la nada y se me debe hacer el don del ser momento tras momento. $Y$ sin embargo, este ser vano es un ser y por eso yo toco a cada instante la plenitud del ser" (Stein, 1996, p. 72). Así, pues, el auto descubrimiento radical del yo se da en el encuentro consigo mismo, ser finito, que en la misma precariedad es consciente de "tocar" la plenitud de ser. Es decir, la misma precariedad de ser propio del yo, está abierta a la trascendencia y reclama el fundamento. Al respecto, le damos nuevamente la palabra a Stein: "En mi ser yo me encuentro entonces con otro ser que no es el mío, sino que es el sostén y el fundamento de mi ser que no posee en sí mismo ni sostén ni fundamento [...] el fundamento y autor de mi ser, como de todo ser finito, puede ser a fin de cuentas, únicamente un ser que no es un ser recibido, como todo ser humano: este ser debe existir necesariamente por sí mismo; es un ser que no puede -como todo lo que tiene un comienzo- dejar de ser, sino que es necesario" (Stein, 1996, p. 76).

Una muestra más del trascender de la memoria, que San Agustín acuñó en la tradición filosófica, teológica y cultural en la que estamos insertos en el presente. Bien vale rescatar estos pensamientos en la hora actual, cuando existen muchas y variadas reflexiones acerca de la memoria. 


\section{BIBLIOGRAFÍA}

GILSON, E. (1958). La filosofía en la Edad Media (vol. 1). Madrid: Gredos.

LAíN, P. (1954). La memoria y la esperanza. San Agustín, San Juan de la Cruz, Antonio Machado, Miguel de Unamuno. Discurso de recepción pública. Madrid: Real Academia Española.

MARÍAS, J. (2005). Mapa del mundo personal. Madrid: Alianza Editorial.

\section{SAN AGUSTÍN}

— (2012). Confesiones. Traducción de Agustín Úña Juárez. Madrid: Tecnos.

— (1985). La Trinidad. Madrid: Biblioteca de Autores Cristianos.

STEIN, E. (1996). Ser finito y ser eterno. Traducción de Alberto Pérez Monroy. México: Fondo de Cultura Económica. 